В.В. Федько, Д.С. Безуглий

Харківський національний економічний університет ім. С. Кузнеия, Харків

\title{
ПОБУДОВА ВЕБ ЗАСТОСУНКІВ НА ОСНОВІ КОНСТРУКТИВНИХ ЕЛЕМЕНТІВ
}

Розглянуто проблему підбору конструктивних елементів для створення веб застосунків засобами CMS систем. Проаналізовано основні недоліки технології використання CMS систем під час розробки модулів. Запропоновано систему розширень модулів на основі колекиії програмних хуків та віджетів. Така система прискорює розробку модулів, спрощує роботу з базою даних завдяки інтегрованій ORM системі, допомагає швидко втілювати функиіонал, який є спільним для багатьох модулів. Описано систему оптимізації розробки модулів для сучасних CMS-систем на прикладі Prestashop, яка використовується для швидкої розробки Інтернет-магазинів. Під час дослідження використано технологї̈ PHP, JavaScript (ES6), Smarty, Symfony та методи побудови UML-сиенаріїв використання.

Ключові слова: CMS-система, розробка веб застосунків, програмний модуль, хук в програмуванні, віджет, розширення модуля, Prestashop, Інтернет-магазин.

\section{Вступ}

У поточному стані розвитку сучасних CMSсистем (наприклад Drupal, Prestashop, WooCommerce, Joomla, Magento) підчас розробки модулів спостерігається декілька суттєвих недоліків [1-5].

Першим недоліком є жорстка структура, від якої не можна відходити. Якщо іiї не дотримуватися, то буде неможливою верифікація модуля маркетплейсом.

Другим недоліком є те, що існує декілька версій, але важко постійно відстежувати поточну версію та підлаштовувати модуль під різні системи.

Третім недоліком та складністю є те, що CMSсистеми встановлюються на багатьох серверах, які мають різні налаштування, різні вдосконалення та різні встановлені модулі. Це породжує багато проблем під час розробки.

Наступна проблема полягає у тому, що системи не мають певного фреймворку, який би допомагав та прискорював розробку.

Рішенням цих проблем $є$ побудова нової системи, що буде грати роль фреймворку, який дозволяв би прискорювати розробку веб застосунків. Ця система повинна мати такі властивості:

1) бути незалежною від версії системи та однаково добре працювати на усіх версіях;

2) працювати з базою даних в автоматичному режимі, наприклад після кожної модифікації моделі будь-якого об'єкту змінювати схему відповідної таблиці у базі даних;

3) мати точки розширення. Це може бути зроблено за допомогою хуків, а також завдяки спеціальним розширенням. Такі розширення $є$ підмодулями у модулі. Вони грають роль мікросервісу, який має лімітований функціонал і може “співпрацювати” з іншими застосунками;
4) бути добре документованою та надійно захищеною.

Така система прискорить розробку модулів, спростить роботу з базою даних завдяки інтегрованій ORM-системі, допоможе швидко втілювати функціонал, який є спільним для багатьох модулів.

Об'єктами дослідження $є$ функціональні елементи, архітектура, інформаційне і програмне забезпечення системи удосконалення конструктивних елементів програмних продуктів. Предметною областю дослідження є система оптимізації розробки модулів для сучасних CMS-систем на прикладі Prestashop, яка використовується для швидкої розробки Інтернет-магазинів.

Метою дослідження $є$ вивчення методів удосконалення конструктивних елементів побудови програмних продуктів та їхня реалізація на прикладі CMS-системи Prestashop.

\section{Виклад основного матеріалу}

Виходячи 3 того, що вище сформульована задача відноситься до напрямку розробки програмних продуктів, тому насамперед потрібно виділити такий спектр технологій та інструментів: мову програмування РНР, систему управління базами даних MySql, стандартні HTML, JavaScript та CSS, а також шаблонізатор Smarty. Такий список обгрунтовуються тим, що вдосконалювана система Prestashop написана мовою РНР, тому доцільно й писати застосунки тією самою мовою [6].

Під час розробки для Prestashop дуже часто виникає ситуація, коли засобів самої систем клієнту не вистачає. Тому потрібна інтервенція розробника, щоб виправити той чи інший елемент, або щоб додати новий винятковий функціонал.

Панує думка, що для створення коду під CMSсистему розробнику не потрібно мати високу квалі- 
фікацію. Проте ця думка часто виявляється хибною. Якщо клієнту не потрібно змінювати значну кількість елементів, а наприклад, тільки дизайн, то, можливо, й немає необхідності брати на проект досвідченого розробника. Але якщо потрібно змінювати якісь складні етапи роботи системи, то недосвідчений розробник не зможе швидко зрозуміти функціонування CMS-системи, тому що вона має значну кількість файлів та логіку, яка не є очевидною.

Під час виконання досліджень основною задачею було створення модулів. Тому виникла ідея розроблення універсальних модулів за єдиним шаблоном, однією мовою та щоб не виникало потреби переписувати кожен раз той самий функціонал, який $\epsilon$ дуже схожим під час розробки багатьох модулів. Для цього створено фреймворк для написання модулів.

Для реалізації задачі удосконалення конструктивних елементів побудови програмних продуктів було обрано систему так званих розширень. Ця система дуже схожа з системою роботи модулів у CMSсистемах. Загальна концепція роботи формулюється так. $\mathrm{C}$ основна CMS-система та деяка кількість модулів - елементів розширення цієї системи. Така сама структура була використана підчас розробки застосунку. Модуль виступає як головна система i до неї можуть бути підключені деякі елементи розширення, які є незалежними один від одного і можуть існувати окремо.

Розглянутий вище підхід має такі обмеження. По-перше, розширення не може існувати окремо від модуля, тому не можна взяти й використати без змін код та функціонал розширення, оскільки воно просто не буде працювати. По-друге, розширення не може бути розширеним іншими розширеннями, але воно може мати доступ до інших розширень, які використовуються у модулі. Схема структури модулів подана на рис. 1.

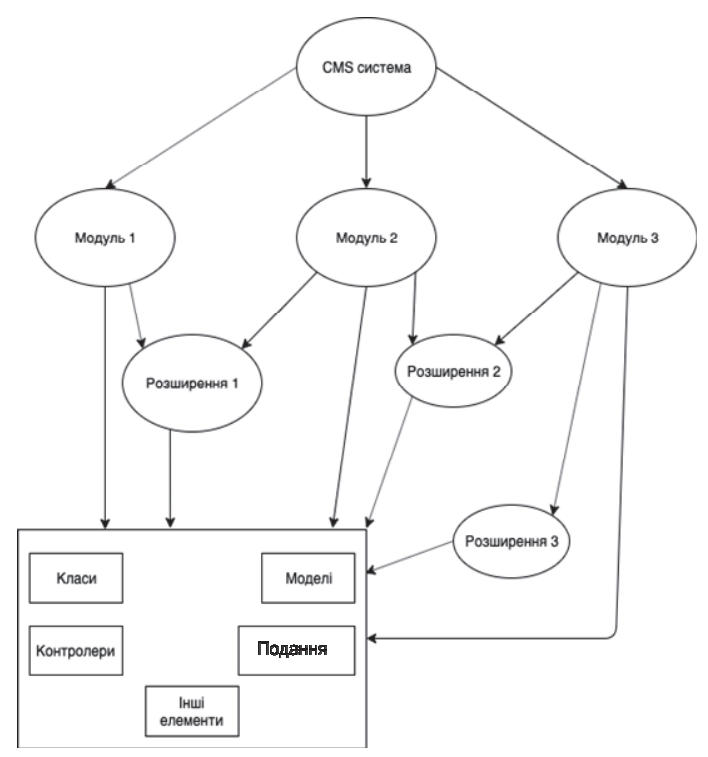

Рис. 1. Структура модулів CMS системи Prestashop
Модуль може використовувати одне або більше розширень. Наприклад, Модуль 1 використовує тільки Розширення 1, а Модуль 2 вже два розширення: Розширення 1 та Розширення 2.

Модель містить набір класів і функцій. У нашому разі конструктивними елементами є модулі та розширення, в інших системах ними можуть бути плагіни чи мікросервіси.

Проаналізувавши підходи сервісів-аналогів було виявлено, що головним їхнім недоліком $\epsilon$ те, що розширення та елементи, які не використовуються модулем та системою в цілому, все одно присутні у системі і їхній код виконується підчас доступу до модуля. Такий підхід не вважається надійним та оптимізованим. Тому було ухвалено рішення використовувати утиліту моніторингу File Watcher [7-8]. File Watcher спостерігає за папкою або набором папок на наявність нових або оновлених файлів. Коли він щось знайде, то передасть ім'я файлу у визначений сценарій, оскільки будь-які дії виконують за сценарієм.

Скрипт для File Watcher реалізовано мовою Node.js. Вiн запускається за допомогою пакета node package manager [9]. Цей скрипт у свою чергу запускає інший скрипт, який написано мовою РНР, а також він перехоплює усі помилки та виключення цього РНР-скрипта. У свою чергу РНР-скрипт приймає декілька параметрів. Першим та обов'язковим $\epsilon$ назва модуля, що розробляється. Це зроблено 3 метою, щоб усі розширення були скопійовані у потрібну директорію. Другий параметр визначає рівень проходу скрипту. За фактом, якщо цей параметр вказано, то ті файли застосунку, що були змінені користувачем, модулем не будуть змінюватися. Отже перевіряється лише їхн наявність. Іншого способу перевірки, нажаль, немає, i, якщо не вказано, то навпаки, усі файли будуть переглядатися скриптом та замінюватимуться новими.

До File Watcher важливо додати ті файли розширень, які використовуються модулем, та видалити ті, які не потрібні.

Більш сучасним є підхід, що використовує поняття composer та namespaces. Composer - це інструмент для керування залежностями в РНР. Він дозволяє оголосити бібліотеки, від яких залежить проект, і буде керувати (встановлювати / оновлювати) їх для проекту [10-11].

Разом із composer також можуть використовуватися простори імен Namespaces. Для цього достатньо лише оголосити директорію та назву namespace у файлі налаштування composer для модуля. Отже, після того, як було оголошено потрібний namespace, слід лише підключити файл автоматичного завантаження компонента composer до скрипта. Далі можна використовувати Namespaces. Вони потрібні для того, щоб можна було зрозуміти, чи додано той чи 
інший файл з розробленого застосунку “Classlib”, чи це файл модуля. Файли розширень, що розробляються, мають свій namespace, який будується за таким патерном: Назва модуля та суфікс "classlib". Таким чином можна зрозуміти, які файли треба підключити із застосунку, а які файли не слід чіпати.

Модулі можуть підписуватися на ці події-хуки. В основі такої моделі лежить патерн проектування Observer. Він $є$ поведінковим шаблоном проектування. Зазначений патерн також відомий як “підлеглі” (Dependents), “видавець-передплатник” (Publisher-Subscriber). Він визначає залежність типу “один до багатьох” між об'єктами таким чином, що при зміні стану одного об'єкта сповіщають усіх залежних від нього про цю подію. Патерн має такі переваги:

1) підтримує принцип вільного зв'язку між об'єктами, які взаємодіють один з одним;

2) дозволяє ефективно передавати дані іншим об'єктам без будь-яких змін у класах Subject або Observer;

3) дає можливість додавати / видаляти спостерігачів в будь-який момент часу [12].

Для керування подіями у застосунку “Classlib" розроблено так званий диспетчер хуків. Це надає такі переваги. По-перше, новий модуль треба успадковувати не від класу Module Prestashop, а від класу модуля, який $є$ у застосунку. Він покращує конструктивні елементи модулів “Classlib”. Цей клас також називається Module, але має інший namespace. Він вже сам по собі поширює клас Module 3 coreчастини Prestashop. Тому проблем з встановленням та публікацією модулів не виникає, оскільки він успадковує всі властивості та методи свого батьківського класу. Клас Module застосунку "Classlib" ініціює у конструкторі диспетчер хуків та має кілька методів для керування ними. Важливо зазначити, що після реєстрації хука у модулі, система Prestashop записує цю інформацію у базу даних та викликає потрібний метод на об'єкті модуля.

У процесі роботи над проектом були використані елементи типу віджет. Він схожий на хук, але процес реєстрації дещо відрізняється. Щоб зареєструвати віджет, треба реалізувати інтерфейс WidgetInterface. У ньому є два методи, які потрібно реалізувати. Ці методи також реалізовані у застосунку, що розробляється. Їх використання викликано проблемою реалізації однієї функції, яка містить логіку роботи з одним віджетом. У разі, коли потрібен віджет, який був би параметризованим та виконував не одну дію, а декілька в залежності від параметрів, виникає проблема. Якщо це робити в основному класі модуля, то при такому підході псується структура та в модуля з'являються не потрібні йому залежності. Тож було ухвалено рішення у той самий диспетчер хуків додати ще й диспетчеризацію від- жетів. Їхнє функціонування дуже схоже. Тому вважається доцільним такий підхід. Єдине чим вони відрізнятися - це базовий клас. Для віджету він $є$ абстрактним класом.

Для демонстрації ефективності спроектованої системи окремо розроблявся той самий модуль двома розробниками, які мають однаковий рівень навичок та компетенцій. За технічним завданням цей модуль має встановлюватися та працювати на системі Prestashop iз API MapaDirect. Також в ньому має бути планувальник завдань Cron, логер та користувач має мати змогу відслідковувати свої замовлення у кабінеті. На рис. 2 подано графіки залежності проценту виконання від часу роботи над проектом.

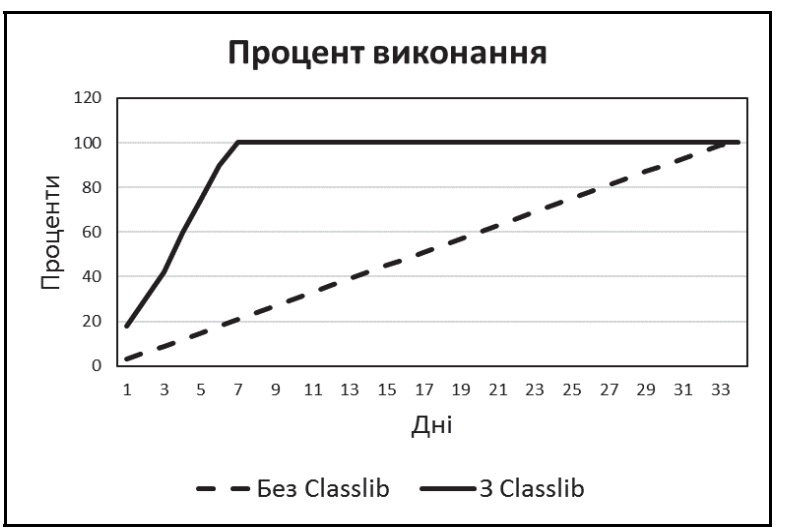

Рис. 2. Динаміка процесів розробки модуля із застосунком та без нього

3 графіків випливає, що модуль, який має описаний вище функціонал, можна розробити за сім днів, а без його використання - близько 34 днів. Це говорить про те, що застосунок дійсно прискорює процес розробки програмних продуктів. Такий результат було досягнуто завдяки повторному використанню розширень, які були описані вище. Якщо взяти до уваги той факт, що потрібно розробляти не один модуль, а набагато більше, то можна зробити висновок, що на розробку модулів витрачається у чотири рази менше часу. Це значною мірою впливає на фінансові показники продуктової компанії.

Важливо зазначити, що застосунок добре протестовано. Тому при моделюванні, розробці та запуску модуля ймовірність того, що нова помилка буде знайдена в одному з розширень модуля, близька до 0. Здійснено дослідження, в якому перевіряється ефективність запропонованого застосунку. Під час розробки модуля, опис якого подано вище, було підраховано кількість завдань розробнику з приміткою “помилка" (тікет). Усі спостереження проводилися протягом місяця (рис. 3).

3 рис. 3 випливає, що $є$ велика різниця між кількістю створених завдань розробнику з приміткою “помилка”. Лише 5 завдань цього типу було створе- 
но для модуля, що розроблявся за допомогою застосунку, який поліпшує конструктивні елементи побудови програмних продуктів, і 28 - без використання цього застосунку.

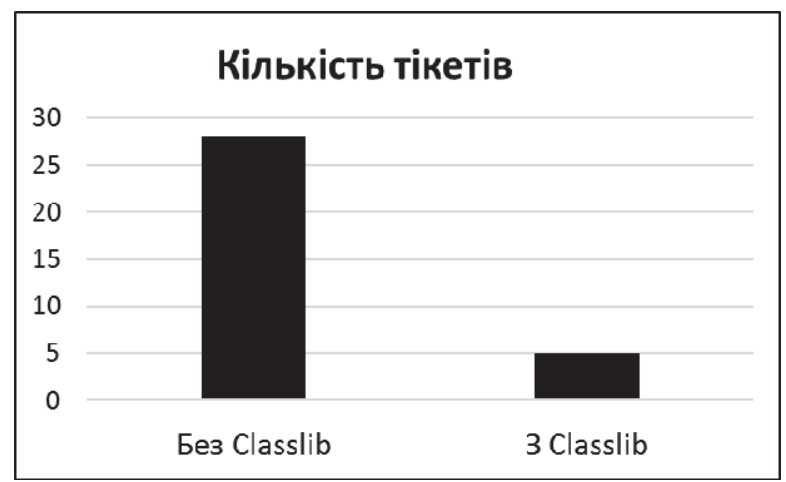

Рис. 3. Порівняння кількості тікетів із приміткою “помилка" під час розробки модуля
Тож, різниця суттєва - майже у 6 разів. Для більш складних модулів ця різниця стає суттєвою, оскільки усі виправлення виконуються за кошти компанії-розробника.

\section{Висновки}

Як результат дослідження отримано систему, яка прискорює розробку модулів Prestashop та удосконалює конструктивні елементи побудови програмних продуктів, додаючи потрібні інструменти розробнику. Вона дозволяє покращити читабельність коду за рахунок об'єднання значної кількості хуків та віджетів в модулі за певною категорією та помістити у різні файли. 3'являється можливість повторно використовувати цей код. Проведені дослідження показали ефективність застосування розглянутого підходу до побудови веб застосунків на основі CMS-систем.

\section{Список літератури}

1. Patel S.K. Joomla, Drupal and WordPress - a statistical comparison of open source CMS / S.K. Patel, V.R. Rathod, S. Parikh // 3rd International Conference on Trendz in Information Sciences \& Computing (TISC2011). - IEEE, 2011. - P. 182187. https://doi.org/10.1109/TISC.2011.6169111.

2. Sistemas de gestión de contenido web: Uso y estudio comparativo inicial de su seguridad. / A. Aledo-Hernández, A. Guillén-Pérez, J. Martinez-Caro, R. Sanchez-Iborra, M. Cano // En XIII Jornadas de Ingeniería telemática. Libro de actas. Editorial Universitat Politècnica de València. - JITEL, 2017. - P. 86-92. https://doi.org/10.4995/JITEL2017.2017.6558.

3. Experiences Creating an Automated Information System for Gathering and Analyzing the Results of Activities of Researchers and Scientific Groups / A. Salnikov, A. Batov, I. Boronin, I. Barabanov // 1st International Conference on Control Systems, Mathematical Modelling, Automation and Energy Efficiency (SUMMA). - Lipetsk, Russia, 2019. - P. 325-328. https://doi.org/10.1109/SUMMA48161.2019.8947512.

4. Wan Shan. Exploring the Advantages of Content Management Systems for Managing Engineering Knowledge in Product-service Systems / Shan Wan, Dongbo Li, James Gao // Procedia CIRP, 56. P. $446-450$. https://doi.org/10.1016/j.procir.2016.10.087.

5. Mirdha A. Comparative analysis of open source content management systems / A. Mirdha, A. Jain, K. Shah // 2014 IEEE International Conference on Computational Intelligence and Computing Research, Coimbatore, 2014. P. 1-4. https://doi.org/10.1109/ICCIC.2014.7238337.

6. Create and develop your business with PrestaShop [Electronic resource]. - Available at: https://www.prestashop.com/en.

7. File Watchers [Electronic resource]. - Available at: https://www.jetbrains.com/help/phpstorm/using-file-watchers.html.

8. File Watcher Utilities [Electronic resource]. - Available: https://sourceforge.net/projects/fwutilities/.

9. Installing Node.js via package manager [Electronic resource]. - Available at: https://nodejs.org/en/download/packagemanager/.

10. Christopher Pitt. Typed PHP: Stronger Types For Cleaner Code / Christopher Pitt. - Appress, 2016. - 96 p. https://doi.org/10.1007/978-1-4842-2114-3.

11. A Dependency Manager for PHP [Electronic resource]. - Available at: https://getcomposer.org/.

12. Ghaleb Taher. Implementing the Observer Design Pattern as an Expressive Language Construct / Taher Ghaleb, Khalid Aljasser, Musab Alturki // Conference: International Conference on Software Engineering Advances (ICSEA 2015), At Barcelona, Spain. P. 463-469. https://doi.org/10.13140/RG.2.1.4879.8164.

\section{References}

1. Patel, S.K., Rathod, V.R. and Parikh, S. (2011), Joomla, Drupal and WordPress-a statistical comparison of open source CMS, 3rd International Conference on Trendz in Information Sciences \& Computing (TISC2011), IEEE, pp. $182-187$. https://doi.org/10.1109/TISC.2011.6169111.

2. Aledo-Hernández, A., Guillén-Pérez, A., Martinez-Caro, J., Sanchez-Iborra, R. and Cano, M. (2018), Sistemas de gestión de contenido web: Uso y estudio comparativo inicial de su seguridad, En XIII Jornadas de Ingeniería telemática (JITEL 2017). Libro de actas, Editorial Universitat Politècnica de València, pp. 86-92. https://doi.org/10.4995/JITEL2017.2017.6558.

3. Salnikov, A., Batov, A., Boronin, I. and Barabanov, I. (2019), Experiences Creating an Automated Information System for Gathering and Analyzing the Results of Activities of Researchers and Scientific Groups, 1st International Conference on Control Systems, Mathematical Modelling, Automation and Energy Efficiency (SUMMA), Lipetsk, Russia. pp. 325-328. https://doi.org/10.1109/SUMMA48161.2019.8947512.

4. Wan, S., Li, D. and Gao, J. (2016), Exploring the Advantages of Content Management Systems for Managing Engineering Knowledge in Product-service Systems, Procedia CIRP, 56. pp. 446-450. https://doi.org/10.1016/j.procir.2016.10.087.

5. Mirdha, A., Jain, A. and Shah, K. (2014), Comparative analysis of open source content management systems, 2014 IEEE International Conference on Computational Intelligence and Computing Research, Coimbatore, pp. 1-4. https://doi.org/10.1109/ICCIC.2014.7238337. 
6. The official site of PRESTASHOP.COM (2019), Create and develop your business with PrestaShop, available at: www.prestashop.com/en.

7. The official site of JETBRAINS.COM (2019), File Watchers, available at: www.jetbrains.com/help/phpstorm/using-filewatchers.html.

8. The official site of SOURCEFORGE.NET (2013), File Watcher Utilities, available at: www.sourceforge.net/projects/fwutilities/.

9. The official site of NODEJS.ORG (2019), Installing Node.js via package manager, available at: www.nodejs.org/en/download/package-manager/.

10. Christopher, P. (2016), Typed PHP: Stronger Types For Cleaner Code, Appress, 96 p. https://doi.org/10.1007/978-14842-2114-3.

11. The official site of GETCOMPOSER.ORG (2019), A Dependency Manager for PHP, available at: www.getcomposer.org/.

12. Ghaleb, T., Aljasser, K. and Alturki, M. (2015), Implementing the Observer Design Pattern as an Expressive Language Construct, International Conference on Software Engineering Advances (ICSEA 2015), Barcelona, Spain, pp. 463-469. https://doi.org/10.13140/RG.2.1.4879.8164.

Надійшла до редколегії 06.01.2020

Схвалена до друку 11.02.2020

\section{Відомості про авторів:}

\section{Федько Віктор Васильович}

кандидат фізико-математичних наук доцент доцент Харківського національного економічного університету ім. С. Кузнеця, Харків, Україна

https://orcid.org/0000-0002-4146-5272

\section{Безуглий Денис Євгенович}

бакалавр

магістрант Харківського національного

економічного університету ім. С. Кузнеця,,

Харків, Україна

https://orcid.org/0000-0002-7627-5022

\section{Information about the authors:}

\section{Victor Fedko}

Candidate of Physics and Mathematics Associate Professor

Senior Lecturer of Simon Kuznets Kharkiv National

University of Economics,

Kharkiv, Ukraine

https://orcid.org/0000-0002-4146-5272

\section{Denys Bezuhlyi}

Bachelor of Computer Science

Postgraduate Student of Simon Kuznets Kharkiv National

University of Economics,

Kharkiv, Ukraine

https://orcid.org/0000-0002-7627-5022

\title{
ПОСТРОЕНИЕ ВЕБ ПРИЛОЖЕНИЙ НА ОСНОВЕ КОНСТРУКТИВНЫХ ЭЛЕМЕНТОВ
}

\author{
В.В. Федько, Д.Е. Безуглый
}

Рассмотрена проблема подбора конструктивных элементов для создания веб приложений средствами CMS систем. Проанализированы основные недостатки технологии использования CMS-систем во время разработки модулей. Предложена система расширений модулей на основе коллекиии программных хуков и виджетов. Такая система ускоряет разработку модулей, упрощает работу с базой данных благодаря интегрированной ORM-системе, помогает быстро реализовывать функиионал, который является общим для многих модулей. Описана система оптимизации разработки модулей для современных CMS-систем на примере Prestashop, которая используется для быстрой разработки Интернет-магазинов. В ходе исследования использованы технологии PHP, JavaScript (ES6), Smarty, Symfony и методы построения UML-сценариев использования.

Ключевые слова: CMS-система, разработка веб приложений, программный модуль, хук в программировании, виджет, расширение модуля, Prestashop, Интернет-магазин.

\section{BUILDING WEB APPLICATIONS BASED ON CONSTRUCTIVE ELEMENTS}

\section{Fedko, D. Bezuhlyi}

The problem of selecting structural elements for creating web applications by means of CMS systems is considered. The main disadvantages of the technology of using CMS systems during the development of modules are analyzed. A system of module extensions based on a collection of software hooks and widgets is proposed. Such a system accelerates the development of modules, simplifies working with the database thanks to the integrated ORM system, and helps to quickly implement the functionality that is common to many modules. A system for optimizing the development of modules for modern CMS systems is described using the example of Prestashop, which is used for the rapid development of online stores. The research used technologies from PHP, JavaScript (ES6), Smarty, Symfony and methods for constructing UML use cases. The application created accelerates the process of software development. This result was achieved through the reuse of the extensions described in the paper. Taking into account the fact that it is necessary to develop more than one module, but much more, it can be concluded that the development of modules takes less time, according to the schedule four times. This greatly affects the financial performance of the product company. The application is well tested. Therefore, when modeling, developing and launching a module, the probability that a new error is found in one of the module extensions is close to 0. A study is conducted to test the effectiveness of the proposed application. As a result of the research, we obtained a system that accelerates the development of Prestashop modules and refines the structural elements of software construction, adding the necessary tools to the developer. It improves the readability of the code by combining a large number of hooks and widgets into modules in a specific category and placing them in different files. You can reuse this code. Studies have shown the effectiveness of the considered approach to building web applications on the basis of CMS systems.

Keywords: CMS system, web application development, software module, hook in programming, widget, module extension, Prestashop, online store. 